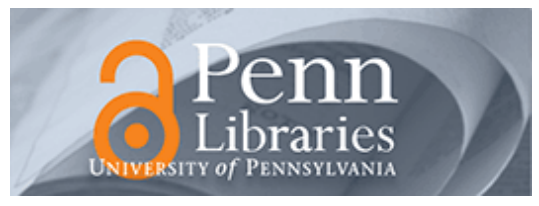

University of Pennsylvania

ScholarlyCommons

Marketing Papers

Wharton Faculty Research

February 1971

\title{
Brief vs. comprehensive descriptions in measuring intentions to purchase
}

J. Scott Armstrong

University of Pennsylvania, armstrong@wharton.upenn.edu

Terry Overton

University of Pennsylvania

Follow this and additional works at: https://repository.upenn.edu/marketing_papers

\section{Recommended Citation}

Armstrong, J. S., \& Overton, T. (1971). Brief vs. comprehensive descriptions in measuring intentions to purchase. Retrieved from https://repository.upenn.edu/marketing_papers/6

Postprint version. Published in Journal of Marketing Research, Volume 8, Issue 1, February 1971, pages $114-117$. Reprinted with permission from the American Marketing Association. The author has asserted his/her right to include this material in ScholarlyCommons@Penn.

This paper is posted at ScholarlyCommons. https://repository.upenn.edu/marketing_papers/6

For more information, please contact repository@pobox.upenn.edu. 


\title{
Brief vs. comprehensive descriptions in measuring intentions to purchase
}

\author{
Abstract \\ Introduction: In forecasting demand for expensive consumer goods, direct questioning of potential \\ consumers about their future purchasing plans has had considerable predictive success [1,2, 4]. Any \\ attempt to apply such "intention to purchase" methods to forecast demand for proposed products or \\ services must determine some way to convey product information to the potential consumer [3]. Indeed, \\ all the prospective consumer knows about the product or service is what he may infer from the \\ information given to him by the researcher. \\ This paper presents a study of the effect upon intention to purchase of this seemingly crucial \\ element-the extent and type of description of the new service. How extensive must the description of the \\ new service be in order to measure intention to purchase?

\section{Comments} \\ Postprint version. Published in Journal of Marketing Research, Volume 8, Issue 1, February 1971, pages \\ 114-117. Reprinted with permission from the American Marketing Association. The author has asserted \\ his/her right to include this material in ScholarlyCommons@Penn.
}




\title{
Brief vs. Comprehensive Descriptions in Measuring Intentions to Purchase
}

\author{
J. Scott Armstrong and Terry Overton \\ Journal of Marketing Research, VIII (February 1971), 114-117 \\ Reprinted with permission from the American Marketing Association
}

\section{Introduction}

In forecasting demand for expensive consumer goods, direct questioning of potential consumers about their future purchasing plans has had considerable predictive success $[1,2,4]$. Any attempt to apply such "intention to purchase" methods to forecast demand for proposed products or services must determine some way to convey product information to the potential consumer [3]. Indeed, all the prospective consumer knows about the product or service is what he may infer from the information given to him by the researcher.

This paper presents a study of the effect upon intention to purchase of this seemingly crucial element - the extent and type of description of the new service. How extensive must the description of the new service be in order to measure intention to purchase?

\section{Research Design}

A single new service was used to study the sensitivity of intention to purchase responses to the extent and type of description. This proposed service, involving the use of a small leased vehicle for urban travel, was designated as the Minicar Lease 'n Park Service.

The study sought to find:

1. What is the level of demand? That is, what proportion of the target market will adopt the service?

2. What is the price elasticity of demand?

3. What types of people are most likely (or least likely) to use this service?

These objectives provide the basis on which the importance of the description will be judged.

To examine the importance of the extent and type of descriptions, two different descriptions, brief and comprehensive, were developed. The brief description was written and could be mailed, while the comprehensive description required attendance of the potential

\footnotetext{
* J. Scott Armstrong is Assistant Professor of Marketing, Wharton School of Finance and Commerce, University of Pennsylvania, and Terry Overton is Instructor, Wharton School. This study was carried out when both authors were associated with the Management Science Center, Wharton School. Research funds were provided by the Urban Mass Transit Administration of the U.S. Department of Transportation.
} 
consumer at a product clinic. Serious problems were anticipated with nonresponse bias for each situation. To control for sampling problems, then, the same subjects were used for both the brief and the comprehensive descriptions.

A sample of screened subjects ${ }^{i}$ was mailed a three-part package. Each of 214 subjects received a copy of the brief description, a questionnaire, and an invitation to attend the product clinic. A cover letter requested that he return the questionnaire before attending this product clinic. At the product clinic, which took place approximately one week after the initial mailing, the subject was asked to fill out the questionnaire a second time. More details on the two descriptions and on the questionnaire are provided below.

\section{Brief Description}

The brief description utilized one-way communication. It was one page of multilithed text accompanied by a picture of the car. The description is reproduced below:

\section{A BRIEF DESCRIPTION OF THE PROPOSED MINICAR SYSTEM}

The proposed Minicar System represents an attempt to solve some of the traffic and air pollution problems in the downtown Philadelphia area. It would also provide another way for people to satisfy their transportation needs.

There would be four key aspects of this Minicar System for a user:

1. A specially designed car: The car would be as wide as a standard car but only half as long. It would have an engine which produces little exhaust and its small size would help relieve parking and traffic congestion. A picture of the proposed vehicle is provided on the following page. [Picture not included in this article.]

The car would utilize new safety features with the result that its safety would at least equal that provided by standard automobiles today. It would have an acceleration equivalent to a standard car and would be capable of expressway speeds.

2. Full insurance and service: The system would provide insurance for the driver and all servicing for the car - cleaning, fuel, maintenance and repairs - while the cars are parked at the minicar garages.

3. Shared use: A subscriber would be guaranteed the use of a car but a specific car would not be assigned to him. He would go to the nearest minicar garage and get the most convenient minicar (which generally would not be the car he last used). Once that car was checked out, it would become his private car until he returned to a minicar garage.

4. Flexible parking: There would be numerous minicar garages around the downtown area of Philadelphia. The user could drop off or pick up a minicar at any of these 
stations. The plan is to have enough garages so that the user in center city will never be farther than two blocks from a minicar station.

The Lease 'n Park service would allow the subscriber use of a car for a fixed monthly fee. These charges would include all costs (ample insurance, fuel, parking, maintenance, etc.).

The goal here was to have the shortest possible description of the key aspects of the system.

The chief advantage of the brief description was that it allowed a relatively low cost survey. The estimated cost per completed questionnaire in this situation was about $\$ 5.50$. This includes the reproduction costs, envelopes, a $\$ 1.00$ "token of appreciation" enclosed with each questionnaire, postage, and cost of labor for sampling and mailing. It does not include the developmental costs for the questionnaire, nor does it include any of the data processing costs. It represents only the costs of collecting the data by mail and is a good approximation of both average and marginal costs.

This questionnaire with the brief description, which was sent by mail, encountered somewhat of a nonresponse problem. About $65 \%$ of the questionnaires were completed and returned.

\section{The Comprehensive Description}

The comprehensive description encouraged two-way communication. Subjects were invited to visit the product clinic at the University of Pennsylvania. Upon arriving, they were guided through an exhibition of 18 wall graphics which explained the key aspects of the system. These charts were grouped in four general topic areas: (1) A Specially Designed Vehicle; (2) How the Minicar System Works; (3) Advantages to the User; and (4) Advantages to the Community.

Table 1

$$
\text { Average Intentions to Purchase }(n=35)
$$

\begin{tabular}{ccc}
\hline $\begin{array}{c}\text { Dollars } \\
\text { per month }\end{array}$ & $\begin{array}{c}\text { "Within the next 12 } \\
\text { months" }\end{array}$ & $\begin{array}{c}\text { "Within the next 4 } \\
\text { years" }\end{array}$ \\
\hline$\$ 60$ & $.39, .45$ & $.61, .63$ \\
$\$ 90$ & $.28, .29$ & $.44, .42$ \\
$\$ 150$ & $.12, .11$ & $.17, .19$ \\
\hline
\end{tabular}

Note: The first figure in each cell was obtained from the brief description and the second from the comprehensive description.

A full-scale prototype of the three-person vehicle was located in the center of the display room. Subjects were invited to sit in this car and operate the controls. Up to this point, it was usual for a substantial amount of two-way communication to take place. 
After viewing the wall charts and inspecting the car itself, the subjects were invited to see a 14-minute movie, an animated sound cartoon which discussed the key features of the minicar system.

At the completion of the movie, the subjects were, en masse, asked to pose questions concerning the system or car. Following this, they were asked to fill out a questionnaire and were reminded that guides were available to answer any questions. This questionnaire was the same as that used for the brief description except for a supplement at the end which asked detailed questions about the vehicle and system.

The comprehensive description discussed many more aspects of the system. It also repeated the key aspects in a number of different ways, to transfer as much information as possible in what was generally about a 35-minute session (vs. about two minutes for the brief description).

The questions posed by those attending the product clinic indicated that they were aware of the key aspects of the system. (In fact, some of the people attending the product clinic would guide other respondents around the exhibit.) The primary focus of the questions was on the car itself. In the researchers' opinion, the car attracted too much attention.

The cost of each completed interview was much more difficult to measure in the case of the comprehensive description. There were substantial fixed costs. The major costs were the preparation of the wall graphics and the film—about $\$ 7,000$. The cost of the prototype car was not included in the calculation since it would have been built whether or not there had been a product clinic.

The variable costs included printing, distribution of invitations, movie projection and sound recording equipment, attendants for the clinic (generally three), space rental, ${ }^{\mathrm{ii}}$ a $\$ 5.00$ honorarium to each person attending the clinic, and, of course, the cost of the questionnaires. This marginal cost per completed interview was about $\$ 36.00$. When the fixed costs are taken into account, the total costs per completed interview are perhaps as high as $\$ 55.00$. ${ }^{\text {ii }}$ The figures of $\$ 36.00$ marginal cost and $\$ 55.00$ average cost contrast with the considerably lower $\$ 5.50$ for the brief version. 


\section{DEMAND SCHEDULE: BRIEF VS. COMPREHENSIVE DESCRIPTIONS ${ }^{\mathrm{a}}$}

(a) "Would subscribe within the next 4 years"

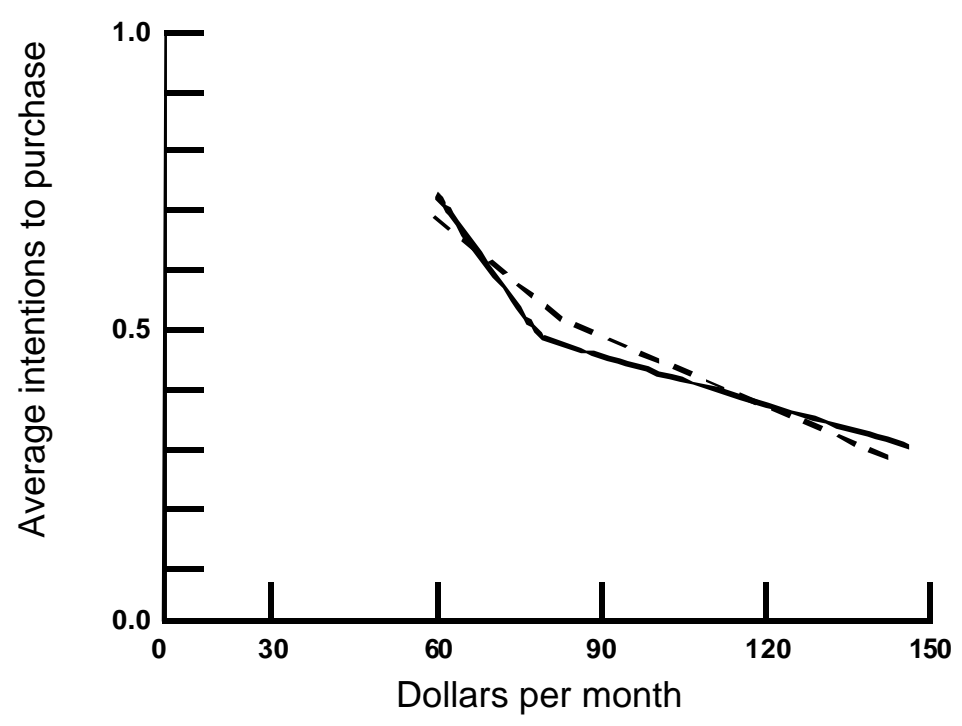

(b) "Would subscribe within the next 12 months"

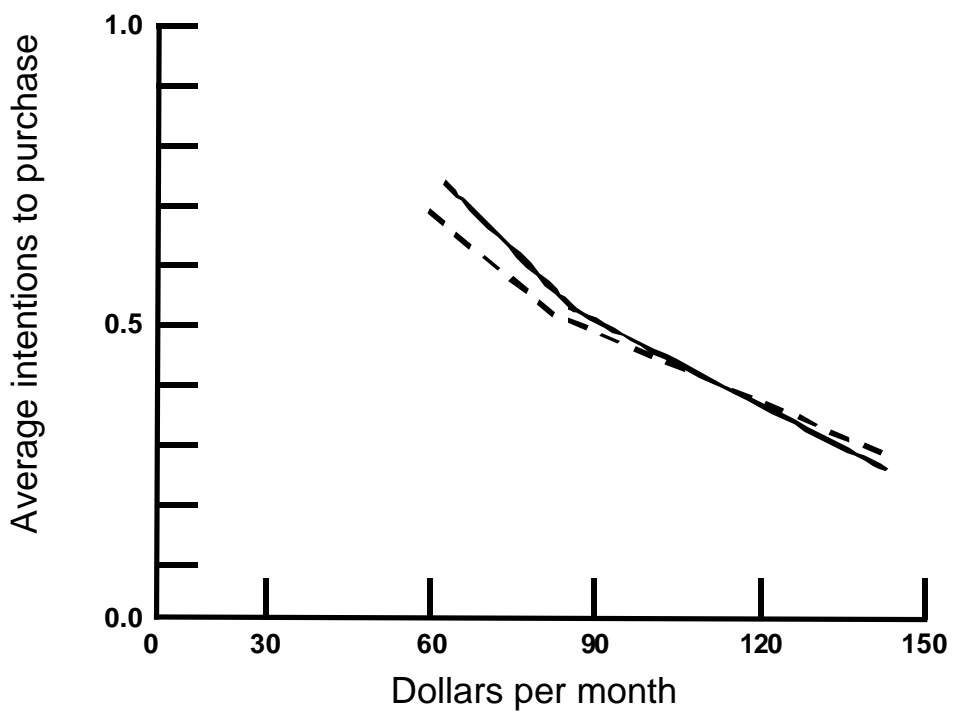

${ }^{a}$ Dotted line represents the brief description and solid line rep resents the comprehensive description

A serious problem was encountered with nonresponse bias. Only about $25 \%$ of those invited to the product clinic came. The effort involved in attending the comprehensive description would seem to be indicative of a high amount of interest. As a result, it was expected that those who did come would not be representative of those invited with respect to their prospects of using the Lease 'n Park service.

\section{The Questionnaire}


Respondents were asked about the prospect that they or some other member of their immediate families would subscribe to the Minicar System within the specified time period (see Appendix for question as stated). Three different prices— $\$ 90, \$ 60$, and $\$ 150$ —end two different time periods - one-year and four-year-were specified. In all then, respondents answered six questions about their prospects of using the Lease 'n Park service.

About 20 minutes were required to fill out the mail version of the questionnaire. The product clinic version required about half an hour, since there were additional questions about the car itself.

\section{RESULTS}

The results are discussed in three parts. First, an attempt was made to see if respondents understood the questionnaire. Second, an examination was made of the demand schedule as predicted by the brief vs. comprehensive descriptions. And finally, an examination was carried out to see whether the two types of description were in agreement with one another for the identification of most likely users of the Lease 'n Park service.

Responses were obtained on both the brief and comprehensive conditions for 40 respondents. Only those who provided answers for all 12 questions were included in the analysis, however, leaving a sample of 35.

\section{Understanding the Questionnaire}

If the respondents understood the questions and were willing to cooperate, certain conditions ought to hold. The two which were examined were: (1) that a subject would be at least as willing to subscribe to the service for $\$ 90$ per month as for $\$ 150$ per month, and similarly at least as willing for $\$ 60$ per month as for $\$ 90$; (2) that he would be at least as likely to subscribe within four years as within one year.

There were no inconsistencies for any of the 35 respondents. This provided some assurance that the respondents did at least understand the questions.

\section{Table 2}

\section{Comparison Of Price Elasticities Over $\$ 60-\$ 150$ Price Range}

\begin{tabular}{ccc}
\hline Time & Brief Description & $\begin{array}{c}\text { Comprehensive } \\
\text { Description }\end{array}$ \\
\hline 1 year & -1.2 & -1.4 \\
4 years & -1.3 & -1.3 \\
\hline
\end{tabular}

\section{Estimating the Demand Schedule}

The demand schedule as estimated by the brief description is presented in the figure along with that estimated by the comprehensive description. The first part presents results for the 
next 4 years; the second presents results for the next 12 months. The data for the figure are presented in Table 1.

It can be seen from the figure that the brief and comprehensive descriptions were in substantial agreement. The results indicate that the estimates of total demand and price elasticity were comparable whether the brief or comprehensive description was used.

Tests were carried out to determine whether the differences between the demand estimates at each price were different. Six comparisons were made-a t-test for each pair of observations in the figure. None of the pairs were significantly different at the .05 level.

Next, an examination was made of price elasticity. ${ }^{\text {iv }}$ Estimates from the brief and comprehensive descriptions were made for the price range from $\$ 60$ to $\$ 150$, providing the comparisons in Table 2.

The differences in the price elasticities were not statistically significant and were of no practical significance in this case.

\section{Identification of Most Likely Users}

Are the brief and comprehensive descriptions in agreement in identifying the most likely users of the Minicar Lease 'n Park service? A simple comparison of the responses is provided in Table 3.

The measures of R2 from Table 3 indicate a substantial amount of agreement among the brief and comprehensive descriptions. In other words, the two descriptions were in substantial agreement in the identification of most and least likely users.

\section{CONCLUSIONS}

In this study about intentions to use a new and expensive transportation service, a questionnaire using a brief description and one using a comprehensive description were successively administered to a group of subjects. The responses from each were separately used to generate estimates of: (1) level of demand at various prices, (2) price elasticities, and (3) identity of likely user groups. No significant differences were found in any of these comparisons. Thus, for the objectives stated in this study, the extent and type of description did not seem to have an appreciable influence upon the results.

Since the conclusions from the brief and comprehensive descriptions were rather similar for a given sample, the choice between them might be made on the bases of costs and of the ability to generalize to the population. On these criteria, the brief description proved to be much superior. Its cost was about one-tenth that of the comprehensive description. Also, the potential problems due to nonresponse bias were fewer, as it achieved a $65 \%$ response vs. a $25 \%$ response for the comprehensive description. 
Table 3

Comparison Of Responses By Individuals

\begin{tabular}{|l|c|c|c|c|}
\hline \multicolumn{1}{|c|}{ Conditions } & $\begin{array}{c}\text { Prospects } \\
\text { higher on } \\
\text { "brief" }\end{array}$ & $\begin{array}{c}\text { No } \\
\text { difference }\end{array}$ & $\begin{array}{c}\text { Prospects } \\
\text { higher on } \\
\text { "Comprehension" }\end{array}$ & $\mathrm{R}^{2}$ \\
\hline \$60; 1 year & 5 & 14 & 16 & .73 \\
\$60; 4 years & 11 & 14 & 10 & .56 \\
\$90; 1 year & 8 & 15 & 12 & .58 \\
$\$ 90 ; 4$ years & 11 & 14 & 10 & .66 \\
\$150; 1 year & 4 & 22 & 9 & .78 \\
\$150; 4 years & 5 & 21 & 9 & .64 \\
\hline
\end{tabular}

Note: The rows are not independent of one another since each uses the same respondents. All levels of R2 are significant at .01 level.

\section{APPENDIX QUESTIONS ON BUYER INTENTIONS}

Assume that "Lease 'n Park" were now available to the public at a price of $\$ 90$ per month (with unlimited use and including parking, fuel, insurance, maintenance and all other costs). Taking everything into account; what are the prospects that you or some other member of your immediate family would subscribe to such a system within the specified time period (assume a terminal is within two blocks of where you work)? Check one item in each column.

Prospects that you would subscribe

sometime within the

$\begin{array}{ll}\text { (a) next } 12 \text { months? } & \text { (b) next } 4 \text { years? }\end{array}$

Absolutely certain that I would subscribe

Practically certain (99 in 100)

Almost sure (9 in 10)

Probable (7 in 10)

Possible (5 in 10)

Some possibility (2 in 10$)$

Very slight possibility (1 in 10)

Almost no chance (1 in 100)

Absolutely no chance at all

[This same question was then asked for a price of $\$ 60$ per month; and then again for $\$ 150$ per month.]

\section{REFERENCES}

Juster, Thomas F. "Consumer Buying Intentions and Purchase Probability: An Experiment in Survey Design," Journal of the American Statistical Association, 61 (September 1966), 658-96.

Katona, George. The Powerful Consumer. New York: McGraw-Hill, 1960. 
Payne, Donald E. "Jet Set, Pseudo-Store and New Product Testing," Journal of Marketing Research, 3 (November 1966), 372-6.

Tobin, James. "On the Predictive Value of Consumer Intentions and Attitudes," Review of Economics and Statistics, 41 (February 1959), 1-11.

${ }^{\mathrm{i}}$ A systematic sampling plan was used to select people from the Philadelphia metropolitan area telephone books. These subjects were then screened by telephone to determine whether they worked in the downtown area of Philadelphia. The mailing was sent to those people who worked in the CBD unless they stated that they did not desire to be contacted again.

ii This is an imputed cost; the space was actually donated by the university.

iii The fixed cost contribution comes from an allocation proportioned across all people attending the product clinic — not just for those people used in the study reported here.

iv The price elasticity was calculated from:

$$
\left[\frac{Q_{2}-Q_{1}}{1 / 2\left(Q_{2}+Q_{1}\right)} \div \frac{P_{2-P_{1}}}{1 / 2\left(P_{2}+P_{1}\right)}\right]
$$

